\title{
Evaluation of Psychosocial Adjustment and Self-Esteem in Perinatally HIV-Infected Adolescents
}

\author{
Orawan Louthrenoo $^{1 *}$, Peninnah Oberdorfer ${ }^{1}$, Linda Aurpibul ${ }^{2}$ and Virat Sirisanthana ${ }^{2}$ \\ ${ }^{1}$ Department of Pediatrics, Chiang Mai University, Chiang Mai, Thailand \\ ${ }^{2}$ Research Institute for Health Sciences, Chiang Mai University, Thailand
}

Received: January 02, 2018; Published: January 11, 2018

*Corresponding author: Orawan Louthrenoo, Department of Pediatrics, Faculty of Medicine, Chiang Mai University, Chiang Mai 50200, Thailand, Tel: 66-53-935412; Email: orawan.l@cmu.ac.th

\section{Abstract}

Introduction: Perinatally HIV-infected children are now surviving through adolescence with advances in antiretroviral therapy and medical health care; however, the nature of the disease may have a variety of impacts on their life. This study aimed to assess psychosocial problems and self-esteem in adolescents with perinatal HIV infection receiving antiretroviral therapy and to compare them with an age- and gender-matched control group.

Methods: A cross-sectional study of 11-18-year-old adolescents who had perinatal HIV infection was conducted. Healthy adolescents, 11-18 years of age, were enrolled as a comparison group. Psychosocial problems and self-esteem of the adolescents from both groups were assessed using the Strengths and Difficulties Questionnaire and the Five-Scale Test of Self-Esteem for Children.

Results: There were 195 participants including 65 perinatally HIV-infected adolescents and 130 healthy controls enrolled to the study. The total psychosocial problem scores of adolescents with perinatal HIV infection were greater than those of their healthy peers without statistical significance. Significant differences were found in the peer problems subscale and prosocial behavior scores between the two groups. However, the total self-esteem scores of HIV-infected adolescents were significantly lower than those of the control group ( $46.14 \mathrm{vs.} \mathrm{50.35;} \mathrm{p}=0.003$ ). There were moderate inverse correlations between the total problem scores and the total self-esteem scores in HIV-infected adolescents ( $\mathrm{r}=$ $-0.60 ; \mathrm{p}=0.01)$.

Conclusion: Perinatally HIV-infected adolescents were at higher risk of developing low levels of self-esteem and greater psychosocial problems than healthy controls. Enhancing self-esteem may help with psychosocial difficulties in these adolescents.

Keywords: Adolescents; Psychosocial adjustment; Self-esteem; HIV infection

Abbreviations: ART: Antiretroviral Therapy; SDQ: Strengths and Difficulties Questionnaire; FSC: Five-Scale Test of Self-Esteem for Children; SD: Standard Deviation

\section{Introduction}

Perinatally HIV-infected children are now surviving through adolescence and beyond with advances in antiretroviral therapy and medical health care. However, the nature of the disease may have a variety of unique impacts on the life of the children and the family. Adolescents with HIV infection share similar stressors experienced by youths with other chronic diseases, including ongoing medical treatment, hospitalizations, and exposure to various procedures [1,2]. Moreover, they often have to cope with grief and loss in the family, stigmatization and illness transmission which may make transition through adolescence more difficult than other chronic illnesses [3,4]. Challenges of adolescent issues including nonadherance, long-term care, and psychosocial issues have been of increasing concerns [3,5-8]. Children and adolescents living with HIV infection frequently have to deal with illness or death of a parent, poverty and disclosure of their own or their parents' HIV status to others. These significant stressors may influence higher risks of mental health problems.

Previous studies have revealed that children and adolescents with HIV infection were at increased risks of psychological and behavioral problems $[9,10]$. In a cohort study, emotional and behavioral problems were found in $24.5 \%$ of HIV-infected adolescents [11]. Similarly, the prevalence of mental health problems was reported to be $29 \%$ in a study of children with perinatal HIV infection [12]. Stigma and depression was found to be related to the quality of life of adolescents with HIV infection [13]. Effects on physical, social and psychological well-being have involved negative feelings such as depression [14], distress and anxiety, which interfere with their self-esteem. Sixty-five percent of 
adults living with HIV/AIDS reported depressive symptoms which were significantly negatively correlated with their self-esteem [15]. Studies of self-esteem in children and adolescents generally focus on those with chronic illnesses [16] but have scarcely been reported in adolescents with HIV infection.

Since performance in school, peer relationship, and motivation to persevere at tasks may be influenced by self-esteem in children, so it can play an important role in child development and functioning. Furthermore, adolescence is also a critical and often a vulnerable period in the development of self-esteem and body image because physical and psychological changes increase the focus on physical appearance while seeking for peer acceptance [17]. Negative selfimage can have a potential effect on psychological and behavioral problems directly related to HIV infection. Consequently, HIV infected patients can be at risk of low level of self-esteem [18]. It is a challenge for health professionals to deliver comprehensive health care which aims both at dealing with the disease and addressing the social and emotional aspects of adolescents who are infected with HIV. Psychological evaluation and promoting self-esteem could improve outcome in adolescents with HIV infection. Therefore, this study aimed to evaluate psychosocial problems and self-esteem in perinatal HIV-infected adolescents receiving antiretroviral therapy compared with those of a healthy control group. The correlation between psychosocial problems and self-esteem in adolescents infected with HIV were also evaluated.

\section{Material and Methods}

\section{Study Population and Design}

A cross-sectional study was conducted in the Pediatric Infectious Diseases Clinic at Chiang Mai University Hospital, a tertiary care hospital in Northern Thailand. Eligible HIV-infected adolescents were enrolled consecutively during 2015. Perinatally HIV-infected adolescents aged 11-18 years who were having antiretroviral therapy (ART), knowing their HIV status and having caregivers who could provide information and accompany them were included. Those with neurological impairment, unable to understand the Thai language or living in an orphanage was excluded from the study. Healthy controls of a similar age and gender without chronic illnesses were selected randomly from a local public school for a comparison group. The adolescents from both groups were asked to complete the self-report questionnaires to evaluate psychosocial problems and self-esteem.

\section{Measurements}

Psychosocial problems in adolescents infected with HIV were assessed using the Strengths and Difficulties Questionnaire (SDQ) $[19,20]$ which comprises 5 scales of a total of 25 items. The selfreport SDQ Thai version, was used in this study [21,22]. The SDQ has high levels of reliability and validity, indicating appropriateness for assessing psychopathology in children and adolescents $[23,24]$. The total problem score is obtained from the sum of 4 subscales including emotional difficulties, conduct difficulties, hyperactivity and peer problems scores. Higher scores indicate more problems or difficulties. On the contrary, the prosocial behavior subscale is assessed separately and higher scores indicate better prosocial behavior. Regarding assessment of self-esteem, the Thai version of the Five-Scale Test of Self-Esteem for Children (FSC) was used in this study [25]. It consists of 5 scales including the social, academic, family, body image and global scales, all of which combine to give the total self-esteem scores. Higher scores indicate higher level of self-esteem. Informed consent from parents or caregivers and assent from adolescents was obtained from all study participants. The study was approved by the Ethics Committee of the Faculty of Medicine, Chiang Mai University.

\section{Statistical Analysis}

Data were analyzed using the SPSS Statistics, Version 22.0 (Armonk, NY: IBM Corp) for Windows. Descriptive variables were presented as mean, standard deviation (SD) and frequency or percentage, as appropriate. Qualitative variables were compared using the chi-square test. For quantitative variables, the student $\mathrm{t}$ test was used to compare the two variables. Pearson correlation was used to assess the association between psychosocial problems and self-esteem scores. A p-value of less than 0.05 was considered statistically significant.

\section{Results}

A hundred and ninety-five participants including 65 HIVinfected adolescents and 130 healthy controls were enrolled onto the study. The mean age of all participants was $14.8 \pm 2.1$ years. Characteristics of adolescents in both groups are shown in Table 1. From the self-report SDQ, adolescents with HIV infection had greater problems scores than healthy peers without statistical significance, except that the peer problems subscale score was significantly higher in HIV-infected adolescents. The Prosocial behavior score of infected adolescents was significantly lower than that of controls, as shown in Table 1. The total self-esteem and all subscales scores from the FSC of adolescents infected with HIV were also lower than those of healthy controls. The total scores as well as the family and body image subscales were significantly lower in the infected group (Table 2). There were moderate inverse correlations between the total SDQ scores and the total self-esteem scores in HIV infected adolescents as shown in Table 3.

Table 1: Characteristics of HIV-infected adolescents and healthy controls $(n=195)$.

\begin{tabular}{|c|c|c|c|}
\hline & $\begin{array}{c}\text { HIV-infected } \\
\text { adolescents } \\
\mathbf{n = 6 5}\end{array}$ & $\begin{array}{c}\text { Healthy } \\
\text { controls } \\
\mathbf{n = 1 3 0}\end{array}$ & $\mathbf{p}$ \\
\hline Age (years), mean (SD) & $14.82(2.09)$ & $14.79(2.16)$ & 0.96 \\
\hline $\begin{array}{c}\text { 11-14 years, n (\%) } \\
\text { 15-18 years, n (\%) }\end{array}$ & $23(35.38)$ & $48(36.92)$ & 0.83 \\
\hline Gender & $34(52.31)$ & $67(51.54)$ & 0.92 \\
Male, n (\%) & $31(47.69)$ & $63(48.46)$ & \\
\hline Female, n (\%) & $8.94(3.09)$ & - & - \\
\hline $\begin{array}{c}\text { Duration of ART } \\
\text { (years), mean (SD) }\end{array}$ & $8.94)$ & \\
\hline
\end{tabular}

ART, antiretroviral therapy 
Table 2: Psychosocial problems and self-esteem scores in HIV-infected and healthy adolescents.

\begin{tabular}{|c|c|c|c|c|}
\hline & $\begin{array}{c}\text { HIV-infected adolescents } \\
\mathbf{n = 6 5}\end{array}$ & Healthy controls n=130 & Mean difference (95\% CI) & $\mathbf{p}$ \\
\hline SDQ, mean (SD) & & & & $0.09(-0.55,0.73)$ \\
\hline Emotional symptoms & $2.83(2.30)$ & $2.74(1.68)$ & $0.02(-0.46,0.51)$ & 0.77 \\
\hline Conduct problems & $3.00(1.83)$ & $2.98(1.51)$ & $0.30(-0.36,0.96)$ & 0.93 \\
\hline Hyperactivity & $3.06(2.34)$ & $2.76(1.88)$ & $0.67(0.23,1.11)$ & 0.37 \\
\hline Peer problems & $3.97(1.35)$ & $3.30(1.53)$ & $-0.76(-1.27,-0.26)$ & 0.003 \\
\hline Prosocial behavior & $6.17(1.56)$ & $6.93(1.75)$ & $1.15(-0.51,2.80)$ & 0.003 \\
\hline Total difficulties score & $12.89(6.00)$ & $11.75(4.27)$ & & 0.17 \\
\hline Self-esteem, mean (SD) & & & $-0.34(-1.05,0.37)$ & 0.35 \\
\hline Social & $9.91(2.43)$ & $10.25(2.35)$ & $-0.67(-1.38,0.04)$ & 0.06 \\
\hline Academic & $8.37(2.32)$ & $9.04(2.38)$ & $-1.16(-1.97,-0.35)$ & 0.005 \\
\hline Family & $13.03(2.77)$ & $14.19(2.66)$ & $-1.21(-1.85,-0.57)$ & $<0.001$ \\
\hline Body image & $4.48(2.04)$ & $5.68(2.18)$ & $-0.70(-1.42,0.02)$ & 0.06 \\
\hline Global & $10.46(2.66)$ & $11.16(2.29)$ & $-4.22(-6.93,-1.50)$ & 0.003 \\
\hline Total self-esteem & $46.14(9.51)$ & $50.35(8.83)$ & \\
\hline
\end{tabular}

SDQ, Strengths and Difficulties Questionnaire; SD, standard deviation

Table 3: Correlation between the psychosocial problems and self-esteem scores in HIV-infected adolescents ( $n=65)$.

\begin{tabular}{|c|c|c|c|c|c|c|}
\hline SDQ & $\begin{array}{c}\text { Emotional } \\
\text { symptoms }\end{array}$ & $\begin{array}{c}\text { Conduct } \\
\text { symptoms }\end{array}$ & Hyperactivity & Peer problems & $\begin{array}{c}\text { Prosocial } \\
\text { behavior }\end{array}$ & $\begin{array}{c}\text { Total difficulties } \\
\text { score }\end{array}$ \\
\hline Self-esteem & & & & & \\
\hline Social & $-0.53^{* *}$ & $-0.47^{* *}$ & $-0.32^{* *}$ & $-0.42^{* *}$ & $0.30^{*}$ & $-0.56^{* *}$ \\
\hline Academic & $-0.36^{* *}$ & $-0.35^{* *}$ & $-0.47^{* *}$ & -0.2 & 0.17 & $-0.47^{* *}$ \\
\hline Family & $-0.47^{* *}$ & $-0.43^{* *}$ & $-0.39^{* *}$ & -0.2 & $0.29^{*}$ & $-0.51^{* *}$ \\
\hline Body image & -0.2 & -0.18 & -0.13 & $-0.51^{* *}$ & 0.17 & $-0.30^{*}$ \\
\hline Global & $-0.43^{* *}$ & $-0.51^{* *}$ & $-0.41^{* *}$ & -0.07 & 0.23 & $-0.50^{* *}$ \\
\hline Total score & $-0.52^{* *}$ & $-0.51^{* *}$ & $-0.44^{* *}$ & $-0.36^{* *}$ & $0.31^{*}$ & $-0.60^{* *}$ \\
\hline
\end{tabular}

SDQ, Strengths and Difficulties Questionnaire ** $p=0.01,{ }^{*} p=0.05$

\section{Discussion}

The findings in this study showed that adolescents with perinatal HIV infection had higher psychosocial problems than healthy peers. The self-report SDQ of infected adolescents revealed greater problems scores than controls without statistical significance, except that the peer problems subscale score was significantly higher and the Prosocial behavior subscale score was lower in infected adolescents. An explanation might be that HIV-infected adolescents had experienced grief and loss of their family members as there were only $17 \%$ of them living with both biological parents at the time of study. Another factor affecting the psychosocial problems is that the majority of them face environmental stressors associated with poverty [26], as they had significantly lower household income than their healthy peers. There were $37 \%$ of the HIV-infected adolescents in this study who had lived with relatives which were mostly their grandparents who earned a low income.

The increased psychosocial problems in HIV-infected adolescents were consistent with a previous study which revealed that HIV-infected adolescents had scored a risk of emotional and behavioral problems, identified from the SDQ as 24.5\% [11]. Stigmatization and discrimination may be one of the factors that these adolescents have experienced so that these could affect peer relationship and Prosocial behaviors [14,27]. In this study, adolescents with HIV infection were found to be at increased risks of having low self-esteem. These findings may be related to the negative consequences of dealing with the diseases, broadly reported in literature as depression and social and emotional isolation. Adolescence is the time of major changes both physically and psychologically. Furthermore, at the time of puberty, body image is of a great concern for the adolescents. Psychologically, adolescents with infection have been worried about their future plans and their own health. These may interfere with their independence and also their self-esteem. Psychosocial support should address ART adherence, future orientation, long-term consequences of risk behaviors, sexual and reproductive health and the coping ability of adolescents with HIV infection [7,14,28].

Moderate inverse correlations between the total SDQ scores and the total self-esteem scores in adolescents with HIV infection were found in this study. This negative correlation is significant 
considering that high psychosocial problems scores indicate low self-esteem. The relationship between self-esteem and depressive symptoms has been documented in many studies involving patients and non-clinical populations [29-31]. The study in adults with HIV infection found an association between self-esteem and depressive symptoms [15]. Low self-esteem in adults with HIV infection [32] is usually due to rejection, loss of social identity, and the physical consequences of HIV disease. Lower self-esteem in adolescents has been reported to be linked to high-risk behaviors in non-clinical adolescents [33]. In a meta-analysis of children and adolescents with chronic illness, low self-esteem was more common in girls than in boys and in adolescents than in children [34]. However, self-esteem was not different between female and male adolescents with HIV infection in this study.

\section{Limitations}

This study evaluates participants of particular age, at adolescence, and assessed both psychosocial problems and selfesteem using self-reporting method, the results being compared with the same method from healthy controls. The correlations of psychosocial problems and self-esteem were also found in this study. However, there were some limitations to be addressed. Firstly, the study was cross-sectional in nature, so the findings may not be viewed for long-term information. Secondly, as the study was performed in a tertiary care center, the results could not be generalized. Thirdly, although self-reporting information may be direct and accurate to some extent, other informants such as caregivers and schools might add more information to the findings.

\section{Conclusion}

Adolescents with perinatal HIV infection were found to be at higher risk of psychosocial problems and low levels of self-esteem in this study. Evaluation of self-esteem and engagement from health services to work on interventions which favor self-esteem may influence the adolescents to cope with the disease. Enhancing selfesteem may help with psychosocial difficulties in these adolescents as well. Follow-up study might provide us more understanding about dynamic of change in self-esteem and would add more useful information to this study. Further explorative study to identify psychosocial problems and associated factors might be warrant.

\section{Acknowledgment}

This work was supported by National Research University Project under Thailand's Office of the Higher Education Commission. The authors would like to thank Dr. Youngyud Wongpiromsarn and Assoc Prof. Suwannee Putthisri for permitting the use of the Strengths and Difficulties Questionnaire, Thai version and the Thai version of the Five-Scale Test of Self-Esteem for Children, respectively. We also would like to express our gratitude to all adolescents and their families who participated in this study.

\section{References}

1. Pinquart M, Shen Y (2011) Behavior problems in children and adolescents with chronic physical illness: a meta-analysis. Journal of Pediatric Psychology 36(9): 1003-1016.

2. Perrin JM, Gnanasekaran S, Delahaye J (2012) Psychological aspects of chronic health conditions. Pediatrics in Review 33: 99-109.
3. Mellins CA, Malee KM (2013) Understanding the mental health of youth living with perinatal HIV infection: lessons learned and current challenges. Journal of the International AIDS Society 16: 18593.

4. Giannattasio A, Officioso A, Continisio GI, Griso G, Storace C, et al. (2011) Psychosocial issues in children and adolescents with HIV infection evaluated with a World Health Organization age-specific descriptor system. Journal of Developmental and Behavioral Pediatrics 32(1): 5255.

5. Mofenson LM, Cotton MF (2013) the challenges of success: adolescents with perinatal HIV infection. Journal of the International AIDS Society 16: 18650.

6. Agwu AL, Fairlie L (2013) antiretroviral treatment, management challenges and outcomes in perinatally HIV-infected adolescents. Journal of the International AIDS Society 16: 18579.

7. Lowenthal ED, Bakeera-Kitaka S, Marukutira T, Chapman J, Goldrath K, et al. (2014) Perinatally acquired HIV infection in adolescents from subSaharan Africa: a review of emerging challenges. The Lancet Infectious Diseases 14(7): 627-639.

8. Mutumba M, Bauermeister JA, Musiime V, Byaruhanga J, Francis K, et al. (2015) Psychosocial challenges and strategies for coping with HIV among adolescents in Uganda: a qualitative study. AIDS Patient Care and STDs 29(2): 86-94.

9. Bomba M, Nacinovich R, Oggiano S, Cassani M, Baushi L, et al. (2010) Poor health-related quality of life and abnormal psychosocial adjustment in Italian children with perinatal HIV infection receiving highly active antiretroviral treatment. AIDS Care 22(7): 858-865.

10. Louthrenoo O, Oberdorfer P, Sirisanthana V (2014) Psychosocial functioning in adolescents with perinatal HIV infection receiving highly active antiretroviral therapy. Journal of the International Association of Providers of AIDS Care 13(2): 178-183.

11. Medin G, Garcia-Navarro C, Navarro Gomez M, Ramos Amador JT, Mellado MJ, et al. (2015) Disease disclosure, treatment adherence, and behavioural profile in a cohort of vertically acquired HIV-infected adolescents. NeuroCo RISpeS study. AIDS Care 28(1): 124-130.

12. Malee KM, Tassiopoulos K, Huo Y, Siberry G, Williams PL, et al. (2011) Mental health functioning among children and adolescents with perinatal HIV infection and perinatal HIV exposure. AIDS Care 23(12): 1533-1544.

13. Andrinopoulos K, Clum G, Murphy DA, Harper G, Perez L, et al. (2011) Health related quality of life and psychosocial correlates among HIVinfected adolescent and young adult women in the US. AIDS Education and Prevention 23(4): 367-381.

14. Mavhu W, Berwick J, Chirawu P, Makamba M, Copas A, et al. (2013) Enhancing psychosocial support for HIV positive adolescents in Harare, Zimbabwe. Plos One 8: e70254.

15. Eller LS, Rivero-Mendez M, Voss J, Chen WT, Chaiphibalsarisdi P, et al. (2014) Depressive symptoms, self-esteem, HIV symptom management self-efficacy and self-compassion in people living with HIV. AIDS Care 26(7): 795-803.

16. Zashikhina A, Hagglof B (2014) Self-esteem in adolescents with chronic physical illness vs. controls in Northern Russia. International Journal of Adolescent Medicine and Health 26(2): 275-281.

17. Sanders RA (2013) Adolescent psychosocial, social, and cognitive development. Pediatrics in Review 34(8): 354-358.

18. Manhas C (2014) Self-esteem and quality of life of people living with HIV/AIDS. Journal of Health Psychology 19: 1471-1479.

19. Goodman R, Ford T, Corbin T, Meltzer H (2004) Using the Strengths and Difficulties Questionnaire (SDQ) multi-informant algorithm to screen looked-after children for psychiatric disorders. European Child \& Adolescent Psychiatry 13 Suppl 2: 25-31.

20. Hysing M, Elgen I, Gillberg C, Lie SA, Lundervold AJ (2007) Chronic physical illness and mental health in children. Results from a large-scale 
population study. Journal of Child Psychology and Psychiatry 48(8) 785-792.

21. Woerner W, Nuanmanee S, Becker A, Wongpiromsarn Y, Mongkol A (2011) Normative data and psychometric properties of the Thai version of the Strengths and Difficulties Questionnaire (SDQ). Journal of Mental Health of Thailand 19: 42-57.

22. Wongpiromsarn Y, Wipulakorn P, Nuanmanee S, Woerner W, Mongkol A (2011) Strengths and Difficulties Questionnaire (SDQ) Thai improved version: change and administration. Journal of Mental Health of Thailand 19: $128-134$.

23. Richter J, Sagatun A, Heyerdahl S, Oppedal B, Roysamb E (2011) The Strengths and Difficulties Questionnaire (SDQ) - self-report. An analysis of its structure in a multiethnic urban adolescent sample. Journal of Child Psychology and Psychiatry 52(9): 1002-1011.

24. Yao S, Zhang C, Zhu X, Jing X, McWhinnie CM, et al. (2009) Measuring adolescent psychopathology: psychometric properties of the selfreport strengths and difficulties questionnaire in a sample of Chinese adolescents. The Journal of Adolescent Health 45(1): 55-62.

25. Putthisri S, Silpakit C (1998) the reliability and validity of Thai version of five-scale test of self- esteem for children. Journal of the Psychiatric Association of Thailand 43: 358-367.

26. Benton TD (2011) Psychiatric considerations in children and adolescents with HIV/AIDS. Pediatric Clinics of North America 58: 989-1002.

27. Hodgson I, Ross J, Haamujompa C, Gitau-Mburu D (2012) Living as an adolescent with HIV in Zambia -- lived experiences, sexual health and reproductive needs. AIDS Care 24(10): 1204-1210.
28. Martinez J, Chakraborty R (2014) psychosocial support for youth living with HIV. American Academy of Pediatrics Committee on Pediatric AIDS. Pediatrics 133(3): 558-562.

29. Orth U, Robins RW, Roberts BW (2008) Low self-esteem prospectively predicts depression in adolescence and young adulthood. Journal of Personality and Social Psychology 95(3): 695-708.

30. Fox PG, Burns KR, Popovich JM, Belknap RA, Frank-Stromborg M (2004) Southeast Asian refugee children: self-esteem as a predictor of depression and scholastic achievement in the U.S. The International Journal of Psychiatric Nursing Research 9(2): 1063-1072.

31. Jagannath V, Unnikrishnan B, Hegde S, Ramapuram JT, Rao S, et al. (2011) Association of depression with social support and self-esteem among HIV positives. Asian Journal of Psychiatry 4(4): 288-292.

32. Visintini R, Bagnato M, Campanini E, Fontana S, Fossati A, et al. (1995) An assessment of self-esteem in HIV-positive patients. AIDS Care 7 Suppl 1: S99-104.

33. Babington LM, Kelley BR, Patsdaughter CA (2009) Self-esteem and risk behaviors of Dominican adolescents. Issues in Comprehensive Pediatric Nursing 32: 131-144.

34. Pinquart M (2013) Self-esteem of children and adolescents with chronic illness: a meta-analysis. Child: Care, Health and Development 39(2): 153-161.

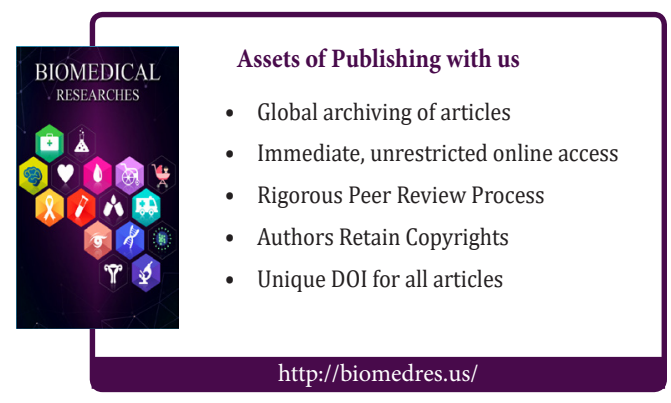

